\title{
STUDI PENERAPAN METODE POHON CONTOH (TREE SAMPLING) DALAM PENDUGAAN POTENSI TEGAKAN HUTAN TANAMAN EKALIPTUS
}

\author{
Arland $\mathbf{S}^{1}$, Emy Sadjati ${ }^{2}$, Muhammad Ikhwan ${ }^{2}$ \\ ${ }^{1}$ Mahasiswa Fakultas Kehutanan Universitas Lancang Kuning \\ ${ }^{2}$ Staff Pengajar Fakultas Kehutanan Universitas Lancang Kuning \\ Jln. Yos Sudarso KM.08 Rumbai, Pekanbaru \\ Email : arland7x@gmail.com,emy_mnhunilak@gmail.com,danmmighwan@yahoo.com
}

\begin{abstract}
Management and exploitation of forest products required for planning to be prepared for sustainable forest exploitation and also taking into account aspects of Sustainability. The so-called aspects are production capabilities, ecological functions and social functions. In order to achieve these matters, appropriate data are needed to present information on the potential for existing forest stands through forest inventory activities. In the inventory activity found some problems that occur in terms of cost, time, problems and human resources needed. Factors that will affect the data we get. These inhibiting factors can be overcome by creating three groups using methods that have been developed both in data retrieval techniques and data processing.The sampling method as a suitable and effective method in which the sampling method used in the inventory activity is a conventional method using a plot or a circle plot with the area and sampling determined according to the age class of the stand. In addition, using conventional methods is another method that also has accurate and precise information. Method of sampling trees. This study aims to the effectiveness and effectiveness of tree sampling methods and circular plot methods, making it easier to find an efficient and effective location in the work area of PT. Perawang Sukses Perkasa Petapahan District. The research was conducted in the plantation of industrial plant Ekaliptus (Eucalyptus pellita) located at PT. Perawang Sukses Perkasa Industri Petapahan District, Kampar District, Riau Province. This research was conducted for 2 months ie in May - June 2018. Based on the results of research conducted method of circular plot will be more effective and has a higher level of accuracy than other methods with a value of $2.9 \%$ sampling error. When viewed from a relative point of view, the relative average yield using the tree sampling method of 8 trees is more easily done in a circular manner with a relative value of $200.28 \%$ and accuracy is still accountable.
\end{abstract}

Keywords : Inventory, Forest Potential Potential, Eucalyptus

\section{PENDAHULUAN}

\section{Latar Belakang}

Pada kegiatan pengelolaan dan pengusahaan hasil hutan diperlukan suatu perencanaan yang akan disusun untuk pengusahaan hutan yang bersifat berkesinambungan serta memperhatikan segala aspek kelestariannya. Aspek kelestarian yang dimaksud adalah kelestarian fungsi 
produksi, fungsi ekologis dan fungsi sosial. Untuk mencapai hal tersebut maka diperlukan data yang tepat untuk menyajikan informasi mengenai potensi tegakan hutan yang ada melalui kegiatan inventarisasi hutan.

Untuk menghasilkan data yang tepat dan akurat maka kegiatan inventarisasi harus dilakukan dengan terencana dan terukur. Akan tetapi pada kegiatan inventarisasi ditemukan beberapa masalah yang dihadapi baik pada segi biaya, waktu, geografis dan sumber daya manusia yang dibutuhkan. Faktor-faktor tersebut akan mempengaruhi terhadap data yang kita peroleh.

Faktor-faktor

penghambat tersebut dapat diatasi dengan membuat serangkaian upaya menggunakan beberapa metode yang telah dikembangkan baik pada teknik pengambilan data maupun pengolahan datanya. Dari beberapa metode tersebutpada umumnya metode sampling diketahui sebagai metode yang sesuai dan efektif mengingat beberapa faktor alasan seperti, efisiensi waktu dan biaya, adanya resiko kerusakan yang ditimbulkan pada pengamatan, ketelitian dalam pelaksanaan pengamatan dan ekonomi atau nilai manfaat. Metode sampling yang digunakan pada kegiatan inventarisasi adalah metode konvensional dengan menggunakan plot petak ukur atau plot lingkaran (circular plot) dengan luas dan intensitas sampling yang telah ditentukan sesuai kelas umur tegakan.

Selain menggunakan metode konvensional tersebut ada metode lain yang dianggap mempunyai keunggulan lain dan mampu memberikan hasil yang baik dan cukup akurat yaitu metode tree sampling. Keunggulan pada metode ini adalah penerapannya dilapangan yang lebih sederhana, akurat, cepat, dan lebih mudah dipahami khususnya untuk masyarakat. Namun metode ini perlu adanya pengembangan lebih lanjut agar menjadi alternatif yang lebih baik sehingga metode tree sampling ini dapat dijadikan pembanding khususnya metode konvensional yang selama ini digunakan.

\section{Rumusan Masalah}

Berdasarkan latar belakang yang sudah diuraikan diatas dalam penelitian ini dapat dirumuskan masalah yaitu perlunya pengujian dalam penerapan metode tree sampling dalam memudahkan dan menghitung besarnya 
potensi pada suatu tegakan hutan tanaman khususnya tanaman ekaliptus secara efektif dan efisien dalam segi waktu dan pengerjaannya.

\section{Tujuan Penelitian}

Penelitian ini bertujuan untuk menguji tingkat efisiensi, efektivitas dan ketelitian antara metode tree sampling dan metode circular plot, sehingga diharapkan diperoleh metode inventarisasi hutan yang bersifat efisien, efektif dan teliti di wilayah kerja kawasan hutan tanaman khususnya pada wilayah kerja PT. Perawang Sukses Perkasa Industri Distrik Petapahan.

\section{Manfaat Penelitian}

Pada penelitian ini diharapkan metode tree sampling dapat diterapkan bagi instansi dan peneliti lainnya dalam kegiatan inventarisasi hutan untuk memperoleh data secara efektif, efisien dan akurat.

\section{METODE PENELITIAN}

\section{Tempat dan Waktu Penelitian}

Penelitian ini dilakukan di hutan tanaman industry Ekaliptus (Eucalyptus pellita)yang terletak di PT. Perawang Sukses Perkasa Industri Distrik Petapahan, Kabupaten Kampar,
Provinsi Riau. Penelitian ini akan dilaksanakan selama 2 bulan yaitu pada Mei - Juni 2018.

\section{Bahan dan Alat}

Bahan penelitian yang akan digunakan adalah Tegakan Hutan Tanaman Industri Ekaliptus (Eucalyptus pellita) satu tahun sebelum tebangan, sedangkan alat - alat yang digunakan untuk pengambilan data yaitu phi band, meteran, vertex, kompas, stopwatch, alat tulis, kalkulator, tally sheet dan clinometers.

\section{Metode Penelitian}

\section{Penentuan Contoh}

Dalam penelitian ini, pengambilan contoh dilakukan pada tegakan Ekaliptus pada kelas umur 4 tahun atau satu tahun sebelum masa tebangan dengan luas $17 \mathrm{Ha}$ pada petak TPGE 001101 di areal PT Perawang Sukses Perkasa Industri, Distrik Petapahan. Pada pengambilan unit contoh yang terpilih akan dilakukan dengan menggunakan dua metode penentuan bentuk unit contoh dalam inventarisasi hutan, yaitu metode sampling dimana metode sampling ini terbagi atas circular plot dan metode tree sampling serta 
menghitung populasi dengan metode sensus untuk menghitung efektivitasnya Pengukuran unit contoh yang dilakukan meliputi:

a. Untuk metode circular plot, Petak ukur yang digunakan berbentuk lingkaran dengan luas 0,02 hektar dengan jari-jari $7,9 \mathrm{~m}$. Intensitas sampling yang digunakan sebesar 7\%. Penempatan petak ukur dilakukan dengan metode simple random sampling. Berdasarkan intensitas sampling (IS) yang sudah ditetapkan, maka jumlah unit petak ukur dapat ditentukan dengan rumus :

$$
\mathrm{n}=\mathrm{IS} \times \mathrm{N}
$$

dimana : $n=$ jumlah unit contoh

IS = intensitas sampling (\%)

$\mathrm{N}=$ jumlah unit populasi

$\mathrm{N}$ diperoleh dengan menggunakan rumus :

$$
\mathrm{N}=\frac{\text { luas areal }(\mathrm{Ha})}{\text { luas lingkaran plot }(\mathrm{Ha})}
$$

Dari rumus tersebut dapat diketahui jumlah unit contoh yang dibutuhkan adalah 25 dengan luas areal 0,02 ha.

b. Untuk metode tree sampling jumlah dan penempatan petak ukur disesuaikan dengan metode circular plot. Pengukuran dilakukan pada pohon-pohon terdekat dari pusat pengukuran (6, 8, dan 10 pohon). Dalam hal ini, jumlah pohon yang diukur adalah 6, 8, dan 10 pohon. c. Untuk metode sensus dengan menghitung jumlah populasi yang tersisa dari metode sampling sebelumnya secara menyeluruh.

\section{Pengumpulan Data}

Penelitian ini memerlukan dua macam data, yaitu data primer dan data sekunder.Data primer adalah data yang diperoleh melalui kegiatan pengukuran langsung di lapangan yang meliputi diameter pohon, tinggi pohon, jarak terjauh (untuk metode tree sampling) dan waktu pengukuran pada setiap metode. Data sekunder yang diperlukan meliputi peta kerja dan sumber referensi lainnya tentang inventarisasi hutan.

Pada metode circular plot dilakukan pengukuran diameter setinggi dada (1,30 $\mathrm{m}$ diatas tanah) semua pohon yang masuk dalam petak ukur seluas 0,02 hektar, sedangkan untuk metode tree sampling, pengukuran hanya dilakukan pada pohon-pohon yang terdekat dengan titik pusat pengukuran saja, dalam hal ini pengukuran diameter hanya dilakukan pada 6, 8 dan 10 pohon terdekat dari titik pusat pengukuran. Jarak dan diameter pohon diukur dengan menggunakan meterandan phi band. 


Waktu penyelesaian adalah
$\begin{aligned} & \mathrm{L} \\ & \text { waktu mulai penandaan titik pusat }\end{aligned}$

b) Pendugaan ragam contoh $\left(s_{y}^{2}\right)$

\section{Pengolahan dan Analisis Data}

Pengolahan data hasil pengukuran di lapangan ditujukan untuk memperoleh nilai dugaan volume per hektar. Rumus-rumus yang digunakan untuk mengukur dimensi tegakan Ekaliptus adalah sebagai berikut :

\section{a) Pendugaan Volume}

$$
\mathrm{V}_{\mathrm{jlk}}=\frac{\sum_{i}^{k}=1 V_{i l k}}{n}
$$

Untuk menduga volume tegakan ratarata per ha menggunakan rumus :

$$
\overline{\mathrm{V}}_{\mathrm{lk}}=\frac{\sum_{j}^{n}=1 V_{j l k}}{n}
$$

dimana :

$\mathrm{V}_{\mathrm{jlk}} \quad$ : volume tegakan per ha berdasarkan petak ukur lingkaran ke-j

$V_{\text {ilk }} \quad$ : volume pohon ke-i dari petak ukur lingkaran ke-j

$$
s_{y}^{2}=\frac{\sum_{i=1}^{n} y_{i}^{2}-\frac{\left(\sum_{i=1}^{n} y i\right)^{2}}{n}}{n-1}
$$

dimana :

$\boldsymbol{s}_{\boldsymbol{y}}^{2} \quad$ : ragam contoh $\left(\mathrm{m}^{3}\right)$

n : jumlah unit contoh

c) Ragam dugaan rata-rata contoh $\left(S_{\bar{y}^{2}}\right)$

$$
\begin{gathered}
S_{\bar{y}^{2}}=\frac{S_{y^{2}}}{n} \\
S_{y}=\sqrt{S_{\bar{y}^{2}}} \\
S_{y^{2}}=\frac{\sum_{i=1}^{n} y_{i^{2}}-\left(\left(\sum_{i=1}^{n} y_{i}\right)^{2} / n\right)}{n-1}
\end{gathered}
$$

dimana :

$S_{\bar{y}} \quad$ : simpangan baku populasi

\section{d) Selang Kepercayaan Total Populasi}

Rumus untuk menghitung selang kepercayaan total populasi adalah

$$
\bar{y} \pm\left(t_{\left(\frac{\alpha}{2}, n-1\right)} \cdot S_{\bar{y}}\right.
$$


e) Kesalahan Contoh/Sampling Error (Se)

$$
\mathrm{SE}=\frac{\left(t_{a / 2 . n-1} \cdot S_{\bar{y}}\right)}{\bar{y}} \times 100 \%
$$

dimana :

$t_{(a / 2)}$ : nilai dari tabel titik kritis distribusi $\mathrm{T}$

Tingkat kepercayaan yang digunakan adalah $95 \%$, sehingga

$\alpha=100 \%-95 \%=0,05$

\section{f) Efisiensi Relatif (ER)}

Rumus untuk menentukan efisiensi berbagai unit contoh adalah :

$E R_{\mathrm{b}-\mathrm{a}}=\frac{S E_{a \times W_{a}}^{2}}{S E_{b}^{2} \times W_{b}} \times 100 \%$

dimana :

$E R_{b-a}$ : efisiensi metode $b$ terhadap metode a

$S E_{a}^{2} \quad$ : kesalahan sampling metode a

$S E_{b}^{2} \quad$ : kesalahan sampling metode b

$\mathrm{W}_{\mathrm{a}}$ : waktu kerja rata-rata metode a

$W_{b}$ : waktu kerja rata-rata metode $b$

- Bila $\mathrm{ER}_{\mathrm{b}-\mathrm{a}}>100 \%$, maka metode

b lebih efisien dibandingkan metode a

- Bila $\mathrm{ER}_{\mathrm{b}-\mathrm{a}}<100 \%$, maka metode a lebih efisien dibandingkan metode $b$

- Bila $\mathrm{ER}_{\mathrm{b}-\mathrm{a}}=100 \%$, maka kedua metode tersebut sama ketelitiannya

Pada ketelitian ini, efisiensi yang dimaksud adalah membandingkan metode-metode unit contoh tree sampling terhadap metode unit contoh lingkaran.

\section{HASIL DAN PEMBAHASAN}

\section{Waktu Kerja Untuk Setiap Metode}

Pengukuran dilakukan oleh tiga orang tenaga kerja. Orang pertama bertugas sebagai pengukur tinggi pohon, orang kedua bertugas sebagai pengukur keliling pohon dan jarak terjauh (pada metode tree sampling), dan orang ketiga bertugas mencatat hasil dari semua pengukuran. Waktu kerja pada setiap metode dapat dilihat pada tabel 3.

Tabel 3. Waktu Kerja Pada Berbagai Metode Inventarisasi

\begin{tabular}{|l|c|c|}
\hline Metode & $\begin{array}{c}\text { Waktu } \\
\text { Total } \\
\text { (menit) }\end{array}$ & $\begin{array}{c}\text { Waktu Rata- } \\
\text { Rata (menit) }\end{array}$ \\
\hline Circular & 356,32 & 14,25 \\
\hline $\begin{array}{l}\text { Tree Sampling 6 } \\
\text { Pohon }\end{array}$ & 110,98 & 4,44 \\
\hline $\begin{array}{l}\text { Tree Sampling } 8 \\
\text { Pohon }\end{array}$ & 135,01 & 5,40 \\
\hline $\begin{array}{l}\text { Tree Sampling } \\
\text { 10 Pohon }\end{array}$ & 166,65 & 6,67 \\
\hline
\end{tabular}

Dari tabel diatas dapat dilihat bahwa pengukuran dengan menggunakan metode circular plot mempunyai waktu kerja yang lebih lama dibandingkan dengan metode tree sampling. Hal ini disebabkan karena banyaknya jumlah pohon yang harus 
diukur dalam petak ukur lingkaran 0,02 $\mathrm{Ha}$ tersebut. Untuk metode tree sampling, waktu kerjanya relatif sama dan lebih cepat penerapannya karena jumlah pohon yang diukur dalam satu petak ukur sudah ditentukan yaitu 6,8 dan 10 pohon serta penentuan batas pohonnya juga lebih mudah karena cukup dekat dari titik pusat pengukuran.

\section{Sebaran Kelas Diameter Tegakan Ekaliptus}

Data pengolahan hasil sebaran pada kelas diameter tegakan ekaliptus dapat dilihat pada tabel 4 dibawah ini.

\section{Tabel 4. Frekuensi Diameter Pada Tegakan Ekaliptus}

\begin{tabular}{|c|c|c|c|}
\hline No & Kelas (cm) & Frekuensi & Frekuensi (\%) \\
\hline 1 & $6,6-7,8$ & 9 & 1,4 \\
\hline 2 & $7,9-9,1$ & 21 & 3,3 \\
\hline 3 & $9,2-10,4$ & 28 & 4,4 \\
\hline 4 & $10,5-11,7$ & 89 & 14,1 \\
\hline 5 & $11,8-13,0$ & 143 & 22,7 \\
\hline 6 & $13,1-14,3$ & 229 & 36,3 \\
\hline 7 & $14,4-15,6$ & 89 & 14,1 \\
\hline 8 & $15,7-16,9$ & 14 & 2,2 \\
\hline 9 & $17,0-18,2$ & 4 & 0,6 \\
\hline 10 & $18,3-19,5$ & 4 & 0,6 \\
\hline & Total & 630 & 100 \\
\hline
\end{tabular}

Dari tabel di atas dapat dilihat bahwa ukuran diameter 13,1 - 14,3 memiliki jumlah persentase terbesar dengan nilai $36,3 \%$ kemudian kedua pada diameter 11,8 - 13,0 dengan nilai $22,7 \%$, kemudian ketiga pada diameter
10,5 - 11,7 dan 14,4 - 15,6 dengan nilai $19,7 \%$.

\section{Sebaran Kelas Tinggi Tegakan Ekaliptus}

Data pengolahan hasil sebaran pada kelas tinggi tegakan ekaliptus dapat dilihat pada tabel 5 dibawah ini.

Tabel 5. Frekuensi Tinggi Pada Tegakan Ekaliptus

\begin{tabular}{|c|c|c|c|}
\hline No & Kelas (m) & Frekuensi & Frekuensi (\%) \\
\hline 1 & $9,3-10,4$ & 5 & 0,8 \\
\hline 2 & $10,5-11,6$ & 8 & 1,3 \\
\hline 3 & $11,7-12,8$ & 0 & 0,0 \\
\hline 4 & $12,9-14,0$ & 9 & 1,4 \\
\hline 5 & $14,1-15,2$ & 15 & 2,4 \\
\hline 6 & $15,3-16,4$ & 21 & 3,3 \\
\hline 7 & $16,5-17,6$ & 77 & 12,2 \\
\hline 8 & $17,7-18,8$ & 225 & 35,7 \\
\hline 9 & $18,9-20,0$ & 245 & 38,9 \\
\hline 10 & $20,1-21,2$ & 25 & 4,0 \\
\hline & Total & 630 & 100 \\
\hline
\end{tabular}

Dari tabel diatas dapat di lihat bahwa sebaran dengan tinggi 18,9 20,0 meter memiliki nilai persentase terbesar yaitu $38,9 \%$, kemudian yang kedua pada kelas tinggi 17,7 - 18,8 meter sebesar $35,7 \%$ dan yang ketiga pada kelas tinggi pohon $16,5-17,6$ meter sebesar $12,2 \%$.

\section{Sebaran Kelas Volume Tegakan Ekaliptus}

Data pengolahan hasil sebaran pada kelas volume tegakan ekaliptus dapat dilihat pada tabel 6 dibawah ini. 
Tabel 6. Frekuensi Volume Pada Tegakan Ekaliptus

\begin{tabular}{|c|c|c|c|}
\hline No & $\begin{array}{c}\text { Kelas } \\
\text { Volume } \\
\left(\mathrm{m}^{3}\right)\end{array}$ & Frekuensi & Frekuensi (\%) \\
\hline 1 & $\begin{array}{c}0,02- \\
0,06\end{array}$ & 31 & 4,9 \\
\hline 2 & $\begin{array}{c}0,07- \\
0,11\end{array}$ & 59 & 9,4 \\
\hline 3 & $\begin{array}{c}0,12- \\
0,16\end{array}$ & 166 & 26,3 \\
\hline 4 & $\begin{array}{c}0,17- \\
0,21\end{array}$ & 255 & 40,5 \\
\hline 5 & $\begin{array}{c}0,22- \\
0,26\end{array}$ & 99 & 15,7 \\
\hline 6 & $\begin{array}{c}0,27- \\
0,31\end{array}$ & 16 & 2,5 \\
\hline 7 & $\begin{array}{c}0,32- \\
0,36\end{array}$ & 1 & 0,2 \\
\hline 8 & $\begin{array}{c}0,37- \\
0,41\end{array}$ & 3 & 0,5 \\
\hline & Total & 630 & 100 \\
\hline
\end{tabular}

Dari tabel diatas dapat di lihat bahwa volume $0,17-0,21 \mathrm{~m}^{3}$ memiliki nilai persentase terbesar yaitu 40,5\%, kemudian yang kedua terdapat pada kelas volume $0,12-0,16 \mathrm{~m}^{3}$ dengan persentase sebesar $26,3 \%$ dan yang ketiga pada kelas volume 0,22-0,26 $\mathrm{m}^{3}$ dengan persentase sebesar $15,7 \%$.

\section{Pengukuran Volume}

Pada pendugaan volume pohon diperoleh nilai volume rata-rata per plot, volume per hektar dan potensi tegakan untuk seluruh kawasan hutan pada masing-masing metode seperti terlihat pada tabel 7 dibawah ini.
Tabel 7. Hasil Perhitungan Nilai Dugaan Volume dan Potensi Tegakan

\begin{tabular}{|l|l|c|c|c|}
\hline No & Metode & $\begin{array}{c}\text { Volume } \\
\text { per plot } \\
\left(\mathrm{m}^{3}\right)\end{array}$ & $\begin{array}{c}\text { Luas } \\
\text { Plot } \\
(\mathrm{Ha})\end{array}$ & $\begin{array}{c}\text { Volume } \\
\text { per } \\
\text { hektar } \\
\left(\mathrm{m}^{3} / \mathrm{Ha}\right)\end{array}$ \\
\hline 1 & Circular & 4,43 & 0,0195 & 227,18 \\
\hline 2 & $\begin{array}{l}\text { Tree } \\
\text { Sampling } \\
6\end{array}$ & 0,98 & 0,0022 & 445,45 \\
\hline 3 & $\begin{array}{l}\text { Tree } \\
\text { Sampling } \\
8\end{array}$ & 1,37 & 0,0062 & 220,97 \\
\hline 4 & $\begin{array}{l}\text { Tree } \\
\text { Sampling } \\
10\end{array}$ & 1,71 & 0,0173 & 98,28 \\
\hline 5 & Sensus & - & - & 295,04 \\
\hline
\end{tabular}

Dari hasil perhitungan pada tabel 7 volume per plot tertinggi adalah metode Circular Sampling dengan nilai sebesar 4,43 $\mathrm{m}^{3}$ dan yang terendah adalah meetode Tree Sampling 6 pohon dengan nilai sebesar 0,98 $\mathrm{m}^{3}$. Kemudian untuk volume per hektar tertinggi adalah pada metode Tree Sampling 6 pohon dengan nilai sebesar 445,45 $\mathrm{m}^{3}$ dan yang terendah adalah metode Tree Sampling 10 pohon dengan nilai sebesar 98,28 $\mathrm{m}^{3}$. Setelah perhitungan volume per hektar maka didapatkan potensi tegakan kawasan seluas 7 hektar.

Pada tabel diatas dapat diketahui hasil potensi tegakan dengan luas kawasan 7 hektar pada metode Circular Sampling sebesar 1590,26 $\mathrm{m}^{3}$, pada metode Tree Sampling 6 sebesar $3118,15 \mathrm{~m}^{3}$, pada metode Tree 
Sampling 8 1546,79 $\mathrm{m}^{3}$, pada metode Tree Sampling 10 sebesar 687,96 $\mathrm{m}^{3}$ dan pada metode Sensus sebesar $2065,29 \mathrm{~m}^{3}$. Dari perhitungan potensi tersebut maka metode Tree Sampling 8 memiliki selisih yang paling kecil dengan metode Circular Plot.

Dari uraian tabel diatas dapat dilihat bahwa adanya perbedaan selisih yang jauh pada volume per hektar dimulai dari metode tree sampling 6, 8, dan 10 dimana terjadi penurunan jumlah volume tiap metodenya, hal ini disebabkan karena karakteristik jarak tanam di lapangan yang berbeda-beda dan ditemukan beberapa pohon yang mati sehingga menyebabkan jarak antara titik pusat ke pohon terjauh menjadi berbeda tiap petak ukur nya. Kemudian pada saat pengolahan data volume, diperlukan data luasan per petak ukur dan jarak antar pusat ke pohon terjauh yang berbeda-beda itu di ambil nilai rata-rata nya pada keseluruhan petak ukur untuk menentukan luas per petak ukur oleh sebab itu luas petak ukur mengalami peningkatan yang besar pada tiap metode. Sehingga pada saat pengolahan, perbandingan antara luas dan volume per plot mengalami selisih yang jauh, semakin tinggi luas petak ukur maka semakin banyak jumlah volume pohon yang tidak terhitung di dalamnya sehingga mengakibatkan volume per hektar nya menurun pada tiap metode tree sampling.

Untuk mengetahui nilai dugaan dengan ketelitian yang tinggi, nilai sampling error (kesalahan) akan mempengaruhi ketelitian metode yang digunakan. Sampling error yang diperoleh akan dipengaruhi oleh nilai ragam dan simpangan baku yang dapat dilihat pada tabel 8.

\section{Tabel 8. Nilai Pendugaan Ragam Contoh Dan Ragam Rata- Rata.}

\begin{tabular}{|l|c|c|c|}
\hline \multicolumn{1}{|c|}{ Metode } & $\begin{array}{c}\text { Ragam } \\
\text { Conto } \\
\mathbf{h} \\
\left(\mathbf{m}^{3} / \mathbf{p l o}\right. \\
\mathbf{t})\end{array}$ & $\begin{array}{c}\text { Ragam } \\
\text { Rata- } \\
\text { Rata } \\
\left(\mathbf{m}^{3} / \mathbf{p l o t}\right)\end{array}$ & $\begin{array}{c}\text { Simpanga } \\
\mathbf{n} \text { Baku } \\
\text { Contoh } \\
\left(\mathbf{m}^{3} / \mathbf{p l o t}\right)\end{array}$ \\
\hline Circular & 0,148 & 0,0059 & 0,0768 \\
\hline $\begin{array}{l}\text { Tree } \\
\text { Sampling 6 }\end{array}$ & 0,026 & 0,0010 & 0,0316 \\
\hline $\begin{array}{l}\text { Tree } \\
\text { Sampling 8 }\end{array}$ & 0,023 & 0,0010 & 0,0316 \\
\hline $\begin{array}{l}\text { Tree } \\
\text { Sampling 10 }\end{array}$ & 0,029 & 0,0011 & 0,0332 \\
\hline
\end{tabular}

Untuk menentukan sampling error pada setiap metode maka dilakukan perhitungan potensi hutan pada selang kepercayaan 95\% $(0,05)$ dengan menggunakan tabel distribusi t dimana jumlah sampel (n) yaitu 25. Maka didapatkan nilai distribusi 1,7108 dan hasilnya pada tabel 9. 
Tabel 9. Nilai Potensi Hutan Pada Selang Kepercayaan 95\%.

\begin{tabular}{|l|l|c|}
\hline No & \multicolumn{1}{|c|}{ Metode } & Potensi \\
\hline 1 & Circular & 0,131 \\
\hline 2 & Tree Sampling 6 & 0,054 \\
\hline 3 & Tree Sampling 8 & 0,054 \\
\hline 4 & Tree Sampling 10 & 0,058 \\
\hline
\end{tabular}

\section{Sampling Error}

Besarnya resiko atau kesalahan sampling bagi sesuatu pengamatan yang masih memenuhi syarat ketelitian berkisar antara 5 persen sampai 10 persen (Sutarahardja, et al, 1982). Hasil perhitungan sampling error pada berbagai macam metode dapat dilihat pada tabel 10.

\section{Tabel 10. Nilai Sampling Error Pada Berbagai Macam Metode}

\begin{tabular}{|l|l|c|}
\hline No & \multicolumn{1}{|c|}{ Metode } & $\begin{array}{c}\text { Sampling Error } \\
\text { (\%) }\end{array}$ \\
\hline 1 & Circular & 2,96 \\
\hline 2 & Tree Sampling 6 & 5,5 \\
\hline 3 & Tree Sampling 8 & 3,94 \\
\hline 4 & Tree Sampling 10 & 3,39 \\
\hline
\end{tabular}

Metode circular sampling memperoleh nilai sampling error terkecil dibandingkan yang lain yaitu $2,96 \%$. Semakin kecil sampling error yang diperoleh maka semakin besar tingkat ketelitian yang diperoleh pada suatu pengukuran. Metode tree sampling 10 memperoleh nilai sampling error terkecil kedua dengan nilai 3,39\%.

\section{Efisiensi Relatif}

Efisiensi relatif dapat diperoleh dengan membandingkan besarnya sampling error dan waktu kerja yang diperlukan dalam kegiatan invetarisasi pada berbagai metode tree sampling dengan metode circular sampling. Hasil perhitungan nilai efisiensi relatif tersebut dapat dilihat pada tabel 11 .

Tabel 11. Nilai Efisiensi Relatif Metode Tree Sampling Terhadap Metode Circular Sampling

\begin{tabular}{|l|lr|c|}
\hline No & \multicolumn{1}{|c|}{ Metode } & \multicolumn{1}{|c|}{$\begin{array}{c}\text { Nilai Efisiensi } \\
\text { Relatif (\%) }\end{array}$} \\
\hline 1 & $\begin{array}{l}\text { Tree Sampling 6 } \\
\text { berbanding 8 }\end{array}$ & 87,5 \\
\hline 2 & $\begin{array}{l}\text { Tree Sampling 6 } \\
\text { berbanding 10 }\end{array}$ & 92,6 \\
\hline 3 & $\begin{array}{l}\text { Tree Sampling 6 } \\
\text { berbanding Circular }\end{array}$ & 172,73 \\
\hline 4 & $\begin{array}{l}\text { Tree Sampling 8 } \\
\text { berbanding 10 }\end{array}$ & 106,1 \\
\hline 5 & $\begin{array}{l}\text { Tree Sampling 8 } \\
\text { berbanding Circular }\end{array}$ & 200,28 \\
\hline 6 & $\begin{array}{l}\text { Tree Sampling 10 } \\
\text { berbanding Circular }\end{array}$ & 186,6 \\
\hline
\end{tabular}

Pada tabel 11 dapat dilihat bahwa hasil nilai efisiensi relatif metode tree sampling 8 pohon lebih efisien dari pada metode lainnya dengan nilai efisiensi relatif tertinggi sebesar 200,28\% dan lebih baik dari metode tree sampling 10 pohon. Maka dari hasil perhitungan yang diperoleh penentuan efisiensi relatif dapat dipengaruhi oleh 3 faktor yaitu pada perhitungan pendugaaan potensi volume tegakan, perhitungan sampling 
error dan waktu kerja yang dibutuhkan.

Potensi tegakan pada metode tree sampling 8 mendekati dengan hasil potensi tegakan pada metode circular sebagai pembanding yaitu 1546,79 $\mathrm{m}^{3}$ dan 1590,26 $\mathrm{m}^{3}$. Waktu kerja yang dibutuhkan pada metode tree sampling 8 lebih cepat dibandingkan dengan metode tree sampling 10 yang dapat dilihat pada tabel 3 dan sampling error metode tree sampling 8 lebih kecil dibandingkan metode tree sampling 6 yang dapat dilihat pada tabel 7 .

Menurut Muhammad Ikhwan (2018), pada penelitian efektivitas dan efisiensi tree sampling di lokasi PT. PSPI Lipat Kain disebutkan bahwa teknik tree sampling dengan 8 unit pohon lebih efisien dari pada teknik circular plot dengan nilai efisiensi relatif adalah $103,62 \%$ dan juga lebih efisien dari pada teknik tree sampling dengan 6 pohon dengan nilai efisiensi relatif adalah $134,34 \%$.

Berdasarkan uraian diatas maka dapat diketahui bahwa metode tree sampling 8 pohon memiliki tingkat efisiensi yang lebih baik dibandingkan dengan metode yang lain karena metode tree sampling 8 pohon memiliki nilai efisiensi relatif yang lebih baik.

\section{KESIMPULAN DAN SARAN}

\section{Kesimpulan}

Kesimpulan yang diperoleh dari penelitian ini adalah sebagai berikut :

Berdasarkan hasil penelitian ini metode circular plot dinilai lebih efektif dan memiliki tingkat ketelitian yang lebih tinggi dari pada metode lain dengan nilai sampling error $2,9 \%$.

Bila ditinjau dari segi efisiensi relatif, hasil nilai efisiensi relatif menunjukkan metode tree sampling 8 pohon lebih praktis digunakan dibandingkan metode circular plot dengan nilai efisiensi relatif sebesar $200,28 \%$ dan kea kuratannya masih dapat dipertanggungjawabkan.

\section{Saran}

Perlu adanya penelitian lebih lanjut dengan menggunakan nilai intensitas sampling yang optimum pada metode tree sampling, sehingga diperoleh ketepatan dan ketelitian yang optimum pada tegakan hutan tanaman Ekaliptus.

\section{DAFTAR PUSTAKA}

Direktorat Jendral Kehutanan. 1974. Surat Keputusan Direktur Jenderal Kehutanan

No.143/KPTS/DJ/I/1974 tentang Peraturan Inventarisasi Hutan Jati 
dan Peraturan Penyusunan Rencana Pengaturan Kelestarian Hutan. Perum Perhutani. Jakarta.

Harbagung. $1985 . \quad$ Cara-cara Inventarisasi Hutan. Badan Penelitian dan Pengembangan Kehutanan. Bogor.

Husch, B. 1987. Perencanaan Inventarisasi Hutan.Ul-press. Jakarta.

Ikhwan, Muhammad. 2018. Efektivitas dan Efisiensi Menggunakan Metode Tree Sampling pada Pendugaan Potensi Tegakan Ekaliptus (Eucalyptus Pellita F.Meull). Pekanbaru. Fakultas Kehutanan Universitas Lancang Kuning

Malamassam, Daud. 2009. Inventarisasi Hutan. Fakultas Kehutanan. Universitas Hasanuddin. Makasar.

Nurhayati. 2008. Studi Perbandingan Metode Sampling Antara Simple Random Dengan Stratified Random: Jurnal Basic Data, ICT Research Center UNAS. Vol.3 (1)

Purwaningrum, Y.N. 2002. Penentuan Intensitas Sampling Optimum Dalam Pendugaan Volume Jati (Tectona grandis L.f) Dengan metode Tree Sampling di KPH Blora PT. Perhutani Unit I Jawa Tengah. Skripsi, Jurusan Manajemen Hutan Fakultas Kehutanan IPB. Bogor. (Tidak Diterbitkan)

Simon, Hasanu. 2007. Metode Inventore Hutan. Yogyakarta. Pustaka Pelajar.
Subhanudin, Muhammad. 2004. Studi Penerapan Metode Pohon Contoh ( Tree Sampling) Dalam Pendugaan Potensi Tegakan Akasia (Acacia mangium Wilid.) Di BPKH Parung Panjang KPH Bogor Perum Perhutani Unit III Jawa Barat. Fakultas Kehutanan. Institut Pertanian Bogor. Bogor.

Sutarahardja, S.S. Hardjorajitno, S. Manan, Ngadino, W. Soekotjo, P. Wiroatmodjo, Y. Setiadi, R. Atmawidjaja, H. B. Nasoetion, dan J. Soediono. 1982. Pedoman dan Petunjuk Inventarisasi Hutan. Direktorat Bina Program Kehutanan Bogor. Bogor.

Sutarahardja, S. 1997. Metode Petak Berubah (tree sampling) Dalam Pendugaan Volume Tegakan Hutan Tanaman. Laboratorium Inventarisasi Hutan. Fakultas Kehutanan. Institut Pertanian Bogor.

Sutarahardja S. 1999. Metode Sampling Dalam Inventarisasi Hutan. Laboratorium Inventarisasi Hutan. Fakultas Kehutanan. Institut Pertanian Bogor.

Yoza, Defri. 2017. Inventarisasi JenisJenis Pohon Di Hutan Wisata Dumai. Pekanbaru: Jurnal IImuIImu Kehutanan 1 (1): 2017 